\title{
Improving SoTL Programs: The Impact of a Student Sector
}

\author{
Angela Miller, BS \\ University of Houston-Clear Lake
}

\begin{abstract}
O' Meara, Terosky, and Neumann (2011) revealed a need to integrate faculty teaching and learning centers with research development programs to further both individual professors' goals of creating innovative pedagogical practices and institutional goals for faculty publication and effective decision making regarding funding allocation. This article suggests that universities implement a scholarship of teaching and learning (SOTL) or teaching-learning enhancement center (TLEC) student sector within these integrated faculty development programs. This will foster more pedagogical ideas and a more democratic institution by giving students a voice in their education while enriching the knowledge of students, faculty, and administrators.
\end{abstract}

Recently a classmate conveyed to me her desire to publish research with a professor. Wanting to incorporate an idea learned from a previously studied discipline (communications) with sociological issues she came across in her graduate studies, she asked me if I knew who to contact to express her desires to publish. Unfortunately, my only advice was to speak to her professors, but it occurred to me there should be a campus organization to pair students and professors for collaboration and publication within and across disciplines.

Professors' responsibilities include the two often conflicting tasks of teaching students in the classroom and publishing in their disciplines. To aid professors in their responsibilities, universities frequently implement professional growth programs, such as faculty development offices, to assist professors in their publication endeavors and, less often, scholarship of teaching and learning (SoTL) or teaching-learning enhancement centers (TLEC) to assist professors with discovering, innovating, and improving teaching methods. Although such pedagogical research benefits students in the classroom and facilitates faculty members' continued academic growth, students also have the potential to benefit from and provide benefits to professional development programs. This paper will demonstrate the need for an enhanced SoTL program that incorporates students, teachers, administrators, and the academic community at large. A SoTL or TLEC student sector has the potential to empower students and give them a voice in their education, expand professors' pedagogical knowledge with student collaboration and publication, encourage a student-centered administration, and further pedagogical discourse among all educators.

\section{Current Model of SoTL Programs}

Faculty responsibilities of teaching and publishing often create tension between institutional goals for publication, recognition, and allocation of limited funds and individual professors' goals to discover effective pedagogical practices to meet student learning needs (O'Meara, Terosky, \& Neumann, 2011). These competing goals take time and resources from the other but share the common goal of "transforming teaching and learning for the better" (O' Meara et al., 2011, p. 51). Professional development centers that only focus on evaluating and improving individuals' teaching methods, without regard to publishing pedagogical research, tend to foster a "narrative of constraint" (O' Meara et al., 2011, p. 47). A narrative of constraint model only addresses professors' pedagogical deficits arising from such external sources as negative student evaluations. Although this model may hold instructors accountable, it also constrains innovative ideas as university 
administrators scrutinize professors' work in the classroom, which tends to decrease instructors' autonomy and creativity. Professional development programs that operate in this narrative of constraint model often lead instructors and administrators to see teaching centers only as remedial programs.

In contrast to that limited model, professional development programs that foster a "narrative of growth" (O'Meara et al., 2011, p. 47), where teachers learn from each other by questioning the effectiveness of teaching methods, discussing innovative pedagogical ideas, reflecting on criticism about their ideas, and incorporating and synthesizing ideas from different disciplines and sources, tends to lead to an atmosphere of individual and institutional development rather than restraint.

\section{Proposed Improvement of SoTL Programs}

The tension between individual and institutional responsibilities need not be seen as a problem but as an opportunity to further professional growth (O'Meara et al., 2011). To further discourse in teaching and learning in the academic community at large, individual goals to develop innovative pedagogies should be tied to institutional goals for academic research and publishing. Such an alliance serves faculty needs for continued learning by fostering development of innovative pedagogical methods and also serves broader university goals for publication and academic recognition by encouraging faculty-student collaboration in pedagogical research and publishing (O'Meara et al., 2011).

\section{Combination of Faculty Development and SoTL Programs}

As evidenced by several universities that have had positive outcomes resulting from integrated professional growth models, combining teaching centers and research development programs into an integrated professional development program would foster a "narrative of growth" (O'Meara et al., 2011, p. 47). The integration of these programs more efficiently facilitates the common goal of improving the quality of instruction. An integrated program can invite teachers with pedagogical ideas to collaborate with other professors to refine and publish their concepts and curriculum designs. While integrated professional development clearly brings advantages to faculty and institutions alike, instituting a third component that includes students can also enhance these integrated professional development programs.

\section{Expanded Focus on Student Involvement}

Within SoTL, the physical space of the classroom acts as a student laboratory for faculty to discover better ways to teach, refine their innovative pedagogical methods, and use faculty development programs to research and publish their pedagogical discoveries, but educators often believe the role of students in the professional growth of teachers should go beyond end of term student evaluations. Although universities sometimes offer professional growth for graduate students by implementing pedagogical courses and programs, they are meant for students' and not teachers' professional growth. $\mathrm{O}^{\prime}$ Meara et al. (2011) state these professional growth programs for students will eventually impact universities because these students of education, "with a little luck . . . will "pay it forward' in their future work as faculty" (p. 62); but these student graduate programs do not have a great impact on the present faculty or institution on their campuses. Just as these programs benefit students as they learn new pedagogical methods, these types of programs can benefit teachers as well. If teachers and administrators view students as consultants rather than passive recipients of information, students will have the potential to offer valuable contributions to pedagogy by informing professors of what helps and hinders their learning. 


\section{Lessons Learned}

As an undergraduate, I often felt like a passive participant simply producing work thrust upon me. In contrast, as a graduate student, I was afforded by some dedicated and supportive professors the opportunity to become a teaching, lab-, and research assistant. As a teaching assistant, I was allowed to join the faculty book club, which introduced me to the value of student input and teaching to a diverse student population. I was able to discuss what I learned from the book with various faculty members, providing me with a more in-depth understanding of the pedagogical theory presented in the literature. As a research and lab assistant, I conducted research with professors and other students, furthering my teamwork and leadership skills. As an assistant to the university's Teaching-Learning Enhancement Center (TLEC), I was able to hone my organizational and professional skills while assisting with faculty workshops, lectures on pedagogy, and conferences about the scholarship of teaching and learning. In addition, I co-authored a chapter that detailed a teacher-student collaboration to redesign a graduate class (Case, Miller, \& Jackson, 2012), which made me aware of the publication process and the importance of collaboration. Consequently, these research and lab experiences helped me realize the benefits I had networking and collaborating with faculty members outside the classroom, as well as the rarity of my student experiences. These volunteer and paid positions not only increased my confidence and afforded me publication opportunities, but they also gave me an insight into pedagogical theory and practices, as well as a better understanding of the university's SoTL program.

\section{A SoTL or TLEC Student Sector}

When I became a TLEC graduate assistant, I had direct contact with the workings of the pedagogical professional development program on campus. This experience furthered my understanding of the goals and necessity of such programs and the extent to which these programs impact student success by facilitating faculty pedagogical knowledge. After delving into the SoTL literature (O'Meara et al, 2011), I realized the importance of the SoTL program in which I became involved and the ways it could benefit all students if they were also involved. Because I am a successful student, faculty took notice of my potential and, therefore, offered me these assistant positions. While I am extremely grateful for these opportunities, I cannot help but feel most students may never enjoy the same benefits I had if faculty members do not recognize them as contributors to the educational process.

The benefits I enjoyed should be extended to all students who would like to become more involved in their learning environment. Regardless of their academic success or educational level, all students have a high stake in their own learning and should have a platform to voice concerns and opinions regarding the way teachers teach them. After seeing the benefits resulting from the integration of faculty professional development programs to further both pedagogical innovation and faculty publication (O'Meara, et al., 2011) and understanding the positive impact professional growth experiences had on my education and professional development, I envision a SOTL student sector or TLEC student branch in an integrated professional development program.

A formal SoTL student sector within SoTL or TLEC programs should be open to all students who are interested. It should be student learning focused, but also a place where faculty and administrators listen and learn from students as well. A SoTL student sector has the potential to incorporate a variety of students' experiences more extensively into pedagogical inquiry beyond the classroom and foster more involvement from students who may develop innovative pedagogical ideas. Rather than pedagogical knowledge flowing only from the top down, by implementing a SoTL student sector or TLEC branch into faculty professional growth 
programs, universities will make pedagogical knowledge transformative, reciprocal, and circular between students, faculty, administrators, and the wider academic community.

\section{Benefits to Students}

Just as my professional development experiences increased my selfefficacy, introduced me to students and faculty outside my discipline, enhanced my collaboration skills, afforded me opportunities to publish, and furthered my pedagogical knowledge, a SoTL student sector in an integrated professional development program has the potential to extend those benefits to every student interested in taking an active part in their education. Similar to my own undergraduate experience of having work thrust upon me, students often feel like passive participants in their education. A formal SoTL student sector could empower students to take more responsibility for their learning as active participants, rather than just passive subjects in pedagogical experiments. Letting students have a voice in their education empowers them to think of innovative ideas that would aid in their personal understanding of the curriculum, ultimately enhancing the learning environment. In addition, giving a voice to students fosters a more democratic campus. Pedagogical ideas from students, especially those who regularly face learning or social obstacles, may have a better chance of influencing educators' approaches to teaching if students are given a formal platform to voice their experiences and opinions (PR Newswire, 2013). If educators take student ideas seriously, students learn their voice and actions can have an impact and potentially increase student self-efficacy.

In addition, a formal SoTL student sector or TLEC student branch inclusive of the entire student body will bring students of different abilities and disciplines together and introduce them to faculty whom they might not otherwise encounter in the classroom. Expanding student networks furthers employment and postgraduate opportunities as students foster professional relationships whose bonds will likely last past graduation and into the workplace; networking with faculty also helps students find professors who may be interested in co-authoring research with them.

Furthermore, a SoTL student sector will enhance students' critical thinking, collaboration, and communication skills. Following the model of teaching centers that bring faculty together to find support, students in the SoTL student sector working with their fellow students and faculty will learn the importance of team collaboration. Since collaboration across disciplines fosters ideas from multiple perspectives (O'Meara, et al., 2011), a discipline-diverse SoTL student sector can foster critical thinking skills as students learn to look at problems from different points of view. Also, working with faculty in a SoTL student sector programs will help students learn academic language to more effectively articulate their pedagogical ideas to faculty.

Moreover, just as graduate programs train teaching assistants (O'Meara, et al., 2011), a SoTL student sector can also facilitate events to develop teaching and research assistants. Students interested in becoming teaching assistants can join the SoTL student sector to learn how to create effective learning environments and interact with students both professionally and ethically. Likewise, although students learn research methods and writing skills in the classroom, a SoTL student sector can more extensively hone these skills as faculty, working more intimately with students, show them more efficient ways to write and conduct research, teaching them the "tricks of the trade," so to speak.

Finally, students involved in the SoTL student sector can learn more about university goals and funding issues and how they impact their educations. If administrators view the SoTL student sector as an open forum where student voices are heard, students can articulate their needs, which may impact administrative decisions. Therefore, a SoTL student sector has the potential to provide students with increased self-efficacy as they convey their own pedagogical ideas, increased 
networking opportunities as they meet students and faculty from different disciplines, and a better understanding of pedagogical practices, collaboration, the publication process, and institutional funding decisions.

\section{Benefits to Faculty and Administrators}

Not only will a SoTL student sector benefit students, but it will also benefit faculty and administrators. First, a SoTL student sector has the potential to provide a way for faculty to get to know their students professionally outside the classroom. O' Meara et al. (2011) suggested those educators who work most closely with students understand student needs more fully, stating "no one is better situated to conduct the scholarship of teaching than those engaged with students on a regular basis" ( $p .59$ ). Getting to know students helps professors better understand their particular students' educational requirements and various learning styles. Students today tend to be more diverse and "sometimes less prepared than in the past" (O'Meara, et al., 2011, p. 52) due to lack of critical thinking skills (Ladson-Billings \& Tate IV, 1995), but social media immerses students in a cultural fusion due to their global social interactions, which provides them with multiple and diverse perspectives (Greenhow \& Robelia, 2009). Therefore, while many students may be less prepared for college in the past, they also tend to be more sophisticated about different perspectives and cultures than their student predecessors.

Understanding the world in which students live helps foster creative pedagogy. Students in a SoTL student sector have the potential to teach instructors about student culture by familiarizing professors with the rapidly changing technology that younger students tend to use extensively and more frequently than faculty (Owston, 1997), so teachers can learn to use technology students already use to enhance their pedagogical methods. Just as students learn the language of academics, students can also teach educators about the informal language students use, often rooted in social media or pop culture, especially music, which can help faculty understand the terms in which students tend to think and communicate.

In addition, differences in student demographics create different cultures on each campus. Therefore, what works with one student population may not work with another. Collaborating with students outside the classroom in a SoTL student sector would help teachers and administrators alike better understand the needs of their particular student population. Working closely with various students from their campus helps professors to present course materials in innovative ways to reach them; learning about individual students' backgrounds, social identities, multiple perspectives, and divergent learning styles helps teachers relate to students in their own social sphere and create learning activities that are meaningful to students' lives (Green, 1999).

Second, an inclusive SoTL student sector would provide professors with student collaborators who differ in ability, race, ethnicity, gender, background, socioeconomic class, and other social identifiers. According to feminist theory, placing marginalized voices front and center can provide and promote different perspectives in any given subject (Brooks \& Hesse-Biber, 2007). Since all students have unique educational experiences, all can contribute to the discourse in pedagogical theory and practice if professors see them, not as passive subjects to be studied, but as co-creators of pedagogical knowledge (O'Meara, et al., 2011). Just as working with other faculty members from different disciplines enhances pedagogical research by extending their repertoire of pedagogical knowledge, working with a diverse student population with multiple perspectives also leads to more effective pedagogies.

Furthermore, because a SoTL student sector might attract those students most interested in professional development, it would widen the pool for faculty to identify potential teaching, research, and TLEC assistants. Assistants can help professors with their responsibilities, thereby freeing professors' time, resources, and efforts to concentrate on more complex teaching and research issues. Teaching 
assistants also answer student questions and act as intermediaries between faculty and students, informing professors of potential student problems in the classroom that they may not otherwise recognize because some students may feel intimidated in voicing their criticisms with their teachers. A SoTL student sector may also help faculty and administrators identify TLEC assistants who can help organize meetings, lectures, and other TLEC events. As student assistants learn new skills, faculty members and the institution benefit because professors can produce more work with student help.

Working and collaborating with individual students naturally leads to publication opportunities. A SoTL student sector can provide professors with students, who have the ability to conduct research and write academically, by facilitating student workshops geared toward teaching students effective and professional research methods and writing skills to prepare them for publishing their work. As students learn new skills, teachers can benefit by having more professionally trained students to help conduct pedagogical research and create manuscripts for publication. Therefore, not only do students gain professional skills through collaboration with faculty, but also, collaborating with students for publication furthers professors' goals of creating new, effective pedagogies and institutional goals of publishing for the wider academic world.

Moreover, since those who work with students closely tend to understand their needs (O'Meara et al., 2011), there is the potential to foster a more studentcentered administration and encourage sounder funding decisions and faculty development strategic planning. If administrators take a hands-on approach with the SoTL student sector and get to know their students, administrators may consider student input more often to balance university goals and funding with student needs.

Finally, a SoTL student sector can benefit faculty and administrators by helping dispel the myth that universities develop teaching and learning centers only to address pedagogical problems in the classroom, much as students and teachers often perceive campus writing centers as remedial for students with writing deficiencies (O'Meara et al., 2011). However, just as campus writing centers benefit even experienced student writers through discussion and collaboration with a writing tutor, professors benefit from teaching and learning centers if teachers understand the complex nature of teaching involves continued learning as a life-long process. Contrary to perceiving teaching and learning centers as remedial, teachers and administrators should see these professional development centers as safe spaces to discuss, debate, and share ideas to further innovative pedagogies (O'Meara et al., 2011).

To support professors' continued learning, a SoTL student sector can provide professors with a ready-made student population on which to test innovative pedagogical methods before bringing them to the classroom. If professors know they can have access to students outside the classroom for pedagogical research, faculty may come to realize the collaborative nature of teaching and learning centers, instead of seeing them only as problem solving facilities. Also, since teaching and learning centers need renewed enthusiasm (O'Meara et al., 2011), the ready-made student population a SoTL student sector can provide teachers with for pedagogical testing will add the much-needed excitement to professional development programs and a reason for all teachers to become involved with these centers, not just those with pedagogical problems.

\section{Conclusion}

A SoTL student sector within an integrated professional development program has the potential to benefit all parties involved in education and foster a more democratic institution through multi-perspective dialogue. Rather than a linear process with a transfer of knowledge from top to bottom, professional development programs should rest on a circular model where students inform faculty and administrators, while students, at the same time, learn about 
professorial responsibilities and administration decision-making. A SoTL student sector can formalize students' input and thrust their ideas into the wider academic world through transformative learning without relying on "luck" to hand down ideas in the future. While an integrated SoTL faculty development program serves important functions for professors and administrators, all parties can benefit if universities incorporate students. Therefore, implementing a SoTL student sector or TLEC student branch as a third component of an integrated faculty development program has the potential to foster a "narrative of growth" rather than a "narrative of constraint" (O'Meara et al., 2011, p. 47).

\section{References}

Brooks, A., \& Hesse-Biber, S. N. (2007). An invitation to feminist research. In S. N. Hesse-Biber \& P. L. Leavy (Eds.), Feminist research practice (p. 1-24). Thousand Oaks, CA: Sage Publications.

Case, K., Miller, A., \& J ackson, S.B. (2012). "We talk about race too much in this class!" Complicating the essentialized woman through intersectional pedagogy. In C. Banks $\&$ S. Pliner (Eds.), Teaching, learning, and intersecting identities in higher education (p. 32-48). New York:

Peter Lang.

Green, F. E. (1999). Brain and learning research: Implications for meeting the needs of diverse learners. Education-Indianapolis, $119,682-687$.

Greenhow, C., \& Robelia, B. (2009). Old communication, new literacies: Social network sites as social learning resources. Journal of ComputerMediated Communication, 14, 11301161. doi: $10.1111 / \mathrm{j} .1083-$

6101.2009.01484.x
Ladson-Billings, G. and Tate IV, W. F. (1995). Toward a critical race theory in education. Teacher's College Record, 7, 47-68.

O'Meara, K. A., Terosky, A. L., \& Neumann, A. (2011). The scholarship of teaching and learning, professional growth, and faculty development. In P. Hutchings, M. T. Huber, \& A. Ciccone (Eds.), Scholarship of teaching and learning reconsidered: Institutional integration and impact (p. 45-68). San Francisco, CA: Jossey-Bass.

Owston, R. D. (1997). The World Wide Web: A technology to enhance teaching and learning? Educational Researcher, 26, 27-33. http://dx.doi.org/10.2307/1176036

PR Newswire. (2013, January 23). New online platform gives college students a voice for change. Education News Today. Retrieved from

http://education.einnews.com/pr_ne ws/133571534/new-online-platformgives-college-students-a-voice-forchange.

Angela Miller, BS is a graduate student in the Sociology Master's program with an emphasis on Women's Studies at the University of Houston-Clear Lake. Aspiring to be a sociology professor, she has worked as a teaching assistant for psychology and women's studies courses, a research assistant in the applied social issues lab, an assistant to the Teaching-Learning Enhancement Center, and a former president of the Gamma chapter of Alpha Kappa Delta, the international sociology honor society. Her research includes the intersection of race and gender issues and social privilege. She also examined generational differences in attitudes regarding the transition from childhood to adulthood. Currently she is conducting research for her thesis regarding to what extent the abortion issue played in the 2012 presidential election.

Author Note Thanks to Dr. Kim Case and Dr. Lillian Benavente-McEnery at the University of Houston-Clear Lake for their thoughtful input, suggestions, feedback, and editing on this manuscript. 